magnesium sulphate was a more selective precipitant than ammonium sulphate, and that its selectivity increased with dilution, doubtless owing to the greatly diminished yield of precipitate. The next two stages (precipitation with sulphuric acid and crystallisation by cooling from $45^{\circ} \mathrm{C}$.) raised the sedimentation constant to $3 \cdot 0-3 \cdot 3 \times 10^{-13}$, and further improved the sharpness of the boundary.

The best two preparations studied appeared to be quite homogeneous. They were both obtained from crystals, one by precipitation by dialysis at $5^{\circ} \mathrm{C}$., and the other by precipitation with magnesium sulphate and recrystallising at room temperature. A higher temperature was avoided since pepsin is slowly converted in solution to particles resembling, at least in size, those which it was desired to remove. The peptic activity of the recrystallised preparation was determined by the non-protein nitrogen method, using casein as substrate, and was found to equal that of Northrop's crystals.

In all the above experiments the $p \mathrm{H}$ was kept at 4-5 during centrifuging, by dilute acetate buffers; $N / 5$ sodium chloride was added to suppress the Donnan effect. A few tests were also done to find the effect of other $p \mathrm{H}$ conditions. An exposure of ten minutes to normal hydrochloric acid, followed by two and a half hours with $N / 10$ hydrochloric acid and $N / 10$ sodium chloride, at a temperature rising to $36^{\circ} \mathrm{C}$., only changed the mean sedimentation constant of the centrifugible part from $3.3 \times 10^{-13}$ to $3 \cdot 2 \times 10^{-13}$, though it became less homogeneous and the absorption of light due to the non-centrifugible particles increased from 3 to 18 per cent. This suggests that a $p \mathrm{H}$ of a little above zero has no instantaneous effect on the molecular weight, but only produces slow acid hydrolysis. In this respect the pepsin protein is unique. An exposure of ten minutes to $p \mathbf{H} 9$, followed by $p H 3 \cdot 6$, caused, on the other hand, the formation of about 50 per cent of an aggregate having a sedimentation constant of about 12, while the rest became very inhomogeneous. The latter treatment corresponds to the instantaneous alkaline inactivation which Northrop ${ }^{3}$ and others have shown to be partly reversible.

J. St. L. Philpot.

IngA-BritTA ERIKSSON-QUENSEL.

Laboratory of Physical Chemistry, University of Uppsala.

$$
\text { Nov. } 11 .
$$

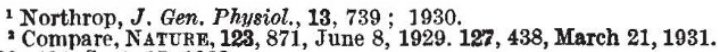
130,434 , Sept. 17,1932 .

Northrop, J. Gen. Physiol., 14, 713; 1931.

\section{Rotation Period of the Planet Venus}

AcCording to my observations, this planet seems to have a very slow rotation, round an axis almost perpendicular to the plane of the orbit. Thus, a dusky spot remained fixed with regard to the terminator for three or four hours on the same dates, as well as on the following days. The behaviour of other spots was analogous; and the interposition of Cytheræan cloud would occasionally render them invisible. The southern regions appeared persistently dusky, while a similar, though smaller, dusky area would, now and then, be seen near the north limb.

These real markings were revealed by the great lightgathering power of the 33-inch telescope, which shows faint half-tones beyond the reach of medium sized in. struments; and they are radically different from the contrast effects seen by Schiaparelli, or from the spots described by others. The equatorial and temperate zones of Venus are more cloud-covered than latitudes beyond $\pm 45^{\circ}$.

Cosmogonical speculation must naturally be considered with the most guarded diffidence. Yet these results seem to support the conclusions reached by Kirkwood in 1864; and as the tidal brake of the sun on the rotation of Venus is now only slightly more effective than the combined brakes of the moon and sun on the rotation of the earth, it seems probable that the rotation of Venus was originally retarded by solar action, when that planet was in a nebulous state, as so ably suggested by Sir George Darwin.

Paris.

E. M. Antoniadi.

Nov. 25.

Dynamics and Mechanism of Aliphatic Substitutions

A SHORT time ago we showed in conjunction with Dr. C. S. Patel ${ }^{1}$ that the known facts concerning reactions of the type of the hydrolysis of ammonium cations ('Reaction $B$ ') could be accommodated by the assumption of a dual mechanism : the reaction could be either bimolecular $(B 2)$, or unimolecular $(B 1)$; for example :

$$
\left.\begin{array}{l}
\text { Alk. } \mathrm{NR}_{3}^{+}+\mathrm{OH}^{-} \rightarrow \text { Alk. } \mathrm{OH}+\mathrm{NR}_{3} \\
\text { Alk. } \mathrm{NR}_{3}^{+} \rightarrow \mathrm{Alk}^{+}+\mathrm{NR}_{3} \text { followed by } \\
\text { Alk }++\mathrm{OH}^{-} \rightarrow \text { Alk.OH (instantaneous) }
\end{array}\right\} .
$$

For a given organic cation, mechanism $B 1$ was expected to be favoured by a low nucleophilic activity in the reagent-anion, as for example towards the right-hand end of the anion series :

$(B 2)$. . $\mathrm{OEt}^{-}, \mathrm{OH}^{-}, \mathrm{OPh}^{-}, \mathrm{OAc}^{-}, \mathrm{Br}^{-}$.

On the other hand, for a given reagent-anion, mechanism $B 1$ should be favoured by constitutional changes in the organic cation, which confer upon the group 'Alk' a greater tendency to pass into the cationic state, for example changes corresponding to passage towards the right in the aralphyl series,

(B 2) . . $\mathrm{CH}_{3}, \mathrm{CH}_{2} \mathrm{Ph}, \mathrm{CHPh}_{2}, \mathrm{CPh}_{3}$. .

or in the alphyl series,

(B 2) . . $\mathrm{CH}_{3}, \mathrm{CH}_{2} \mathrm{Me}, \mathrm{CHMe}_{2}, \mathrm{CMe}_{3}$

At the time of our paper, very little direct dynamical evidence in support of these views was available, but we are now able to furnish dynamical observations relating to each of the three series mentioned above. First, concerning the anion series, we have found in conjunction with Mr. J. L. Gleave, that the anticipated change from bimolecular to unimolecular dynamics can be realised in the example of triethylsulphonium compounds ${ }^{2}$. Secondly, with reference to the aralphyl series, we have observed the required change of mechanism in the case of aralphyltrimethylammonium hydroxides ${ }^{3}$. Thirdly, in relation to the alphyl series, in which the previous indication was merely that methyl and tert.-butyl alcohols are more readily eliminated than primary and secondary alcohols from ammonium hydroxides, we are now able to show that, whereas methyl and ethyl alcohols are eliminated by a bimolecular mechanism, tert.-butyl alcohol is eliminated by a unimolecular mechanism, in the decomposition of trialphyl-sulphonium hydroxides. 